\title{
Prevalence of Peripheral Arterial Disease among Adult Patients Attending Outpatient Clinic at a General Hospital in South Angola
}

\author{
Feliciano Chanana Paquissi, ${ }^{1}$ Arminda Bimbi Paquissi Cuvinje, ${ }^{2}$ \\ and Almeida Bailundo Cuvinje ${ }^{3}$ \\ ${ }^{1}$ Department of Medicine, Clínica Girassol, Luanda, Angola \\ ${ }^{2}$ General Hospital of Huambo, Huambo, Angola \\ ${ }^{3}$ José Eduardo dos Santos University, Huambo, Angola \\ Correspondence should be addressed to Feliciano Chanana Paquissi; fepaquissi@gmail.com
}

Received 31 December 2015; Accepted 24 April 2016

Academic Editor: Leila Beltrami Moreira

Copyright (C) 2016 Feliciano Chanana Paquissi et al. This is an open access article distributed under the Creative Commons Attribution License, which permits unrestricted use, distribution, and reproduction in any medium, provided the original work is properly cited.

\begin{abstract}
Background. Peripheral arterial disease (PAD) is a common manifestation of atherosclerosis, whose prevalence is increasing worldwide, and is associated with all-cause mortality. However, no study has assessed this disease in Huambo. The aim of this study was to evaluate the prevalence of PAD in patients attending an outpatient clinic at a general hospital in Huambo, South Angola. Methods. A cross-sectional study, including 115 patients aged 40 years and older attending an outpatient service. The evaluation included a basic questionnaire for lifestyle and medical history and ankle-brachial index (ABI) measurement using hand-held Doppler. PAD was defined as an ABI $\leq 0.9$ in either lower limb. Results. Of 115 patients, $62.60 \%$ were women with a median age of 52.5 (range of 40 to 91 ) years. The prevalence of PAD was 42.6\% (95\% confidence intervals [CI]: 95\%: 33.91-52.17\%). Among patients with PAD, $95.92 \%$ had mild disease and $4.08 \%$ moderate to severe disease. The main risk factor for PAD was age ( $\geq 60$ years) $\left(\chi^{2}=3.917, P \leq 0.05\right)$. The prevalence was slightly higher in men and hypertensive subjects, but without statistical significance with ORs of 1.5 (95\% CI: 0.69-3.21) and 1.42 (95\% CI: 0.64-3.17), respectively. Hypertension was also high in the group (66.95\%). Conclusion. The prevalence of PAD was $42.6 \%$, higher in those aged 60 years and older. More studies, with representative samples, are necessary to clarify PAD prevalence and associated risk factors.
\end{abstract}

\section{Introduction}

Peripheral arterial disease (PAD) is an important manifestation of atherosclerosis, which in 2010 was estimated to affect more than 202 million people worldwide [1]. From 2000 to 2010 , the number of people with the disease increased by $28.7 \%$ and $13.1 \%$ in low- and high-income countries, respectively [1]. It affects about $4.3 \%$ of Americans aged 40 years and older [2], reaching $12.29 \%$ and $29 \%$ in those over 60 and 70 years of age, respectively $[3,4]$.

The presence of PAD is an important marker of cardiovascular risk $[5,6]$ and is associated with increased all-cause and cardiovascular mortality [7-9]. PAD is independent risk factor for several other negative outcomes such as left ventricular hypertrophy and heart failure [10, 11]; it increases twice the risk of left main coronary artery and multiple vessels involvement, in patients with coronary artery disease (CAD) undergoing coronary angiography [12], and, by functional limitations it imposes, is associated with depression and loss of quality of life $[13,14]$.

The main risk factors are advanced age ( $>65$ years), smoking, diabetes, hypertension, and chronic kidney disease $[3,15$, 16]. Other risk factors are dyslipidemia, vitamin D deficiency, hyperhomocysteinemia, female sex, and black race/ethnicity [16-19].

In sub-Saharan Africa, there are few studies about PAD; however, between 1990 and 2010, the PAD was, with atrial fibrillation, the factor with the highest relative increase in 
the burden of cardiovascular diseases in the region [20]. The prevalence of PAD in different studies has varied depending on the age of the group, the presence or absence of risk factors like diabetes and hypertension in the studied population, and the diagnostic test used. Numerous studies have shown the black ethnicity as a risk factor for PAD, increasing twice the risk and affecting younger patients, even when adjusted for other cardiovascular risk factors that also occur with higher prevalence in blacks than other races [2, 21]. In a study with patients with an average age of 62.4 years, at South Africa, the prevalence of PAD was 29.3\% [22]; and in another study with diabetic patients, in Nigeria, the prevalence was higher reaching $52.5 \%$ [23], showing a prevalence significantly high compared to studies with other populations of the same average age.

Despite a high prevalence, and being CAD risk equivalent, these patients are often overlooked, and only a quarter of patients are submitted to treatment [4, 24, 25]. In Angola, particularly in Huambo, no study was found about the prevalence of PAD. The aim of this study was to assess the prevalence of PAD in patients attending an outpatient clinic at South Angolan hospital.

\section{Materials and Methods}

2.1. Type and Population of The Study. This is a cross-sectional study, with 115 patients aged 40 years and older, seen at the outpatient medical care service in the General Hospital of Huambo, in September 2015. Huambo is a province of southern Angola, with an area of $34.274 \mathrm{~km}^{2}$ and a population of $\sim 1.8$ million inhabitants [26]. The General Hospital of Huambo is a tertiary unit, whose outpatient medical care service attends on average 2.4 thousand patients a month, aged 18 years and older. Despite being conceived as a tertiary level hospital, most patients are of primary care profile and seek assistance by spontaneous demand due to subacute or mild symptoms, which under normal conditions would be assessed at basic health units. However, due to weak structuring of the basic health services, there is this flow diversion to the hospital of greater complexity. Since they do not meet criteria to be attended in the emergency department, they are evaluated at the outpatient service. Therefore, most patients seek assistance without a previously diagnosed chronic disease, for follow-up, and are seen in general medicine consultation. Among patients with previous diagnosis are those with surgical pathology in evaluation for elective surgery and those in postorthopedic trauma followup.

For the study, all adults aged 40 years and older that appeared for consultation during the period of data collection (in September) were invited to participate. Those with any difficulty of measuring blood pressure in 4 limbs were excluded. Data of 118 patients were collected, but 4 of them were excluded due to incomplete or erroneous data. So, the final analysis included a total of 115 patients. Despite a considerable average number of consultations per month, the sample was small because most people seeking care were below 40 years, reflecting the age pyramid of the population in the country, where children and young adults are the majority.
Another reason is that, due to the significant burden of trauma in the population, a considerable number of subjects in postorthopedic trauma follow-up were excluded due to the difficulty of measuring blood pressure in 4 limbs, in the presence of orthotics and synthetic material.

2.2. Study Variables. Data collection included a basic questionnaire with open-ended questions, applied by trained interviewers, consisting of basic questions on the following variables: age, sex, smoking history, personal history of diabetes, hypertension, cerebrovascular or coronary artery disease, and use of medications.

The vascular examination was performed with the patient in the supine position, after at least 10 minutes of rest. Systolic blood pressure (SBP) was measured in brachial artery of each upper limb and at the dorsal or posterior tibial arteries in lower limbs, using hand-held vascular Doppler (BT 200V, $8 \mathrm{MHz}$; Bistos Co., Ltd., Korea) and a sphygmomanometer calibrated and certified by the National Institute of Metrology, Quality, and Technology (INMETRO) of Brazil. The anklebrachial index (ABI) was calculated by dividing SBP on each lower limb by the higher SBP in the arm, according to the specific guidelines $[27,28]$. PAD was defined by an ABI $\leq 0.9$ or greater than 1.3 in at least one lower limb or prior revascularization for PAD $[4,19]$. Subjects with PAD were stratified into three categories of severity according to the value of the ABI: mild (ABI between 0.70 and 0.9 ); moderate (ABI between 0.4 and 0.69 ); and severe or critical limb ischemia $(\mathrm{ABI}<0.4)$.

2.3. Statistical Analysis. The prevalence of PAD was described in absolute and relative numbers, and continuous variables were expressed as median. The prevalence of PAD was calculated in the overall group, specific to age and sex, with respective 95\% confidence intervals. Comparison between categorical variables was examined using chi-square, adopting a level of significance for $P<0.05$. All statistical analyses were performed using a public domain statistical program (OpenEpi version 3.03a).

2.4. Ethics and Data Collection. The study procedures were performed only after informed verbal consent was obtained from the participants or those responsible for them, without any record, because considerable proportion was illiterate, so they do not know how to sign. The confidentiality of patient identification and individual data was guaranteed. All research procedures, including verbal consent procedure, were evaluated and approved by the Scientific and Pedagogical Board of the hospital, that is, the organ responsible for ethical issues in research at the institution, in the absence of formal ethical committee in the province.

\section{Results}

A total of 115 patients were included, the median age was 52.5 years, $62.60 \%$ were women, and all subjects were Africans and blacks. Baseline demographic and clinical characteristics of patients are presented in Table 1. 
TABLE 1: Demographical and clinical characteristics of the study population.

\begin{tabular}{lc}
\hline Characteristics & $n=115$ \\
\hline Age in years, median (range) & $52.5(40-91)$ \\
Female gender (\%) & 62.60 \\
Peripheral arterial disease (\%) & 42.6 \\
Systemic arterial hypertension (\%) & 66.95 \\
Self-reported diabetes (\%) & 6.95 \\
Smoking (\%) & 9.56 \\
\hline Medical therapy (\%) & \\
$\quad$ Angiotensin-converting enzyme inhibitor or & 17 \\
angiotensin receptor blockers & $12 / 4$ \\
Calcium channel antagonists/diuretics & 4 \\
Acetylsalicylic acid & $0 / 0$ \\
Statins/clopidogrel & \\
\hline
\end{tabular}

TABLE 2: Univariate analysis of risk factors associated with peripheral arterial disease in adults of 40 years of age and older, General Hospital of Huambo, Angola, $2015(n=115)$.

\begin{tabular}{lccc}
\hline Factor & OR & $95 \%$ CI & $P$ value \\
\hline Age $(\geq 60$ versus $<60$ years $)$ & $3.917^{*}$ & - & 0.04 \\
Sex (male versus female) & 1.5 & $0.69-3.21$ & 0.39 \\
Hypertension & 1.42 & $0.64-3.17$ & 0.49 \\
\hline
\end{tabular}

OR: odds ratio; CI: confidence interval. ${ }^{*}$ Chi-square.

The prevalence of peripheral arterial disease $(\mathrm{ABI} \leq 0.9)$ was $42.6 \%$ ( $n=49$; 95\% CI: 33.91-52.17\%) (Figure 1); and nobody had an ABI value $>1.3$. Among patients with PAD, 95.92\% had mild disease and $4.08 \%$ had moderate to severe disease. In multivariate analysis, the occurrence of PAD was significantly associated $\left(\chi^{2}=3.917, P \leq 0.05\right)$ with age of 60 years and older ( $60 \%$ versus $37.78 \%)$. There was no significant association between PAD and hypertension (OR: 1.42; 95\% CI: $0.64-3.17$ ) or male sex (OR: 1.5 ; 95\% CI: $0.69-$ 3.21) (Table 2 and Figure 1).

In the group, $66.95 \%(n=77 ; 95 \%$ CI: $58.26-76.52 \%)$ had hypertension; $13.04 \%$ ( $n=15$; 95\% CI: $6.95-20 \%$ ) had prehypertension; $6.95 \%(n=8$; 95\% CI: $2.60-12.17 \%)$ self-reported diabetes, and 9.56\% $(n=11$; 95\% CI: 3.34-15.65\%) reported active smoking. Nobody reported personal history of cerebrovascular or coronary artery disease. Among hypertensive patients, only $35.06 \%$ were in treatment and $10.38 \%$ were with controlled blood pressure $(<140 / 90 \mathrm{~mm} \mathrm{Hg})$, with the most commonly used medications being the renin angiotensin aldosterone system inhibitors, either alone or in combination with diuretics and/or calcium channel antagonists. None of the participants were taking statin or clopidogrel.

\section{Discussion}

In this study, we found prevalence of PAD to be $42.6 \%$, which is more in accordance with Africans studies made in populations with specific risk factors such as diabetes in Uganda (39\%) [29] and Nigeria (40\%) [30] and hypertension

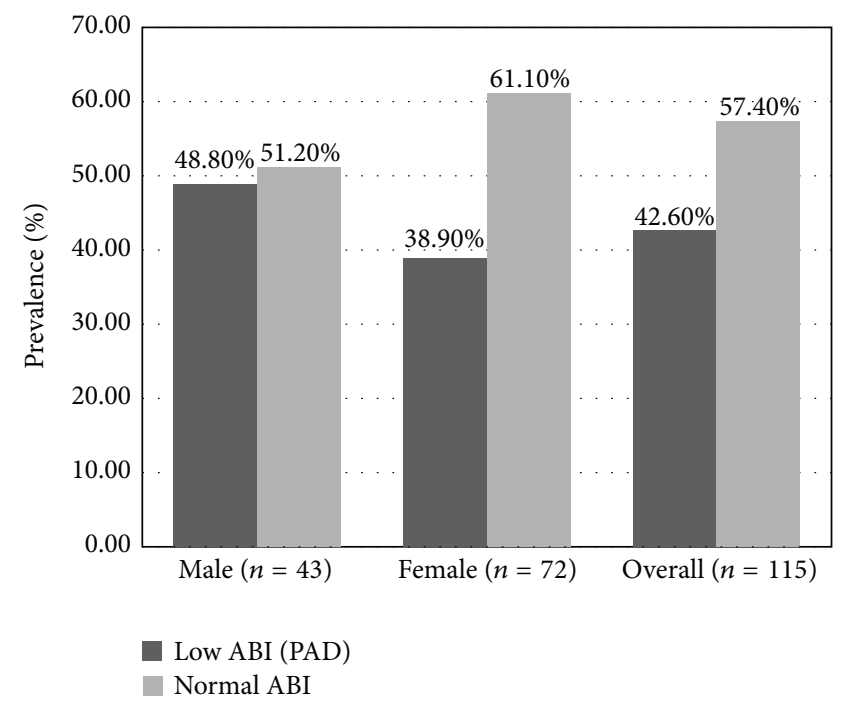

FIGURE 1: Overall, and by gender prevalence of PAD in adults aged 40 years and older. General Hospital of Huambo, Angola, $2015(n=$ 115).

in Nigeria (41.8\%) [31]. However, it is relatively greater than that found in general population studies as that done in Brazzaville (32.4\%) [32], especially considering that the population of this study is of general demand, which should actually be seen in primary care; and considering the average age in this study, prevalence is even higher compared to American populations of same age [2]. There are no other studies with our population to compare with directly, since this is the first study on PAD in the country.

This high prevalence may reflect several factors, such as the racial role in early arterial stiffness [21], to PAD as a target organ damage reflecting misdiagnosis, low treatment, and control of its main risk factors such as hypertension and diabetes $[33,34]$. This is evident looking at the fact that the prevalence of hypertension in the group was high (66.95\%), and of these only $35.06 \%$ and $10.38 \%$ were in treatment and had their blood pressure controlled, respectively. This shows how late health professionals are arriving at diagnosing, treating, and controlling risk factors, when PAD and other target organs' damage are already installed, which is in concordance with that high prevalence found among hypertensive patients in Nigeria [31]. The prevalence of self-reported diabetes was $6.95 \%$ but may be underestimated too, as shown in the study where almost $42.8 \%$ of diabetics were unaware of their status [35].

Unfortunately, it was not possible to study other risk factors for atherosclerosis such as lipid levels, hyperhomocysteinemia, vitamin D deficiency, and some inflammatory markers that could help us understand the reason for such a high prevalence of PAD as found in this study.

In this study, we highlight importance of knowing about the disease as a CAD risk equivalent and independent marker for several clinical outcomes such as increased total and cardiovascular mortality, number of coronary events, and stroke $[5,6,8,36]$, risk of amputation with all social and psychological consequences [14], and even risk of developing 
dementia, as demonstrated in a study population of Central Africa [37]. So, with a simple test (ABI), we could have a window to access the individual cardiovascular and no vascular health [36]. This importance is enhanced because such knowledge would justify changes in patient's approach such as the introduction of statins and platelet antiaggregant for those who were not taking any of these drugs $[19,38]$ and even more rigorous blood pressure target $(<130 / 80 \mathrm{~mm} \mathrm{Hg})$ in individuals who are diagnosed with this CAD risk equivalent [39]. In the present study, no patient with PAD was taking statins or clopidogrel, which shows how the lack of diagnosis was a substrate for the patients remaining without this treatment whose benefit is well established in disease $[19,38]$.

In addition, it is important to emphasize the role of race as a risk factor in the disease, since the black race is associated with increased progression from normal to low ABI [40] and higher prevalence [2], which may explain, in part, a high prevalence found in a relatively young population. Also black patients develop greater need for reintervention and amputation after endovascular procedures [41], longer hospital stay after bypass [42], and higher cardiovascular mortality [43], even after adjusting for other factors, which reflects not only differences in access to health, but a possible role of race as an independent pathophysiological and prognostic factor [42].

\section{Conclusions}

This is the first study on PAD in Huambo and in the country. So, a high prevalence found in this study, despite being with a no representative sample, should be at least a starting point for more studies on the subject to clarify PAD prevalence and associated risk factors.

\section{Abbreviations}

ABI: Ankle-brachial index

CAD: Coronary artery disease

PAD: Peripheral arterial disease

SBP: Systolic blood pressure.

\section{Additional Points}

This is a single center and hospital-based study; so it does not represent the general population of Huambo, even with study population do not present the profile of a tertiary hospital patients. There was no possibility to study the associated risk factors.

\section{Competing Interests}

The authors declare that there are no competing interests regarding the publication of this paper.

\section{Authors' Contributions}

Feliciano Chanana Paquissi performed study design, interpretation of data, writing of the manuscript, and revision of the paper. Arminda Bimbi Paquissi Cuvinje performed study design, data collection, and revision of the paper. Almeida Bailundo Cuvinje performed data collection and revision of the paper.

\section{References}

[1] F. G. R. Fowkes, D. Rudan, I. Rudan et al., "Comparison of global estimates of prevalence and risk factors for peripheral artery disease in 2000 and 2010: a systematic review and analysis," The Lancet, vol. 382, no. 9901, pp. 1329-1340, 2013.

[2] E. Selvin and T. P. Erlinger, "Prevalence of and risk factors for peripheral arterial disease in the United States: results from the National Health and Nutrition Examination Survey, 19992000," Circulation, vol. 110, no. 6, pp. 738-743, 2004.

[3] Y. Ostchega, R. Paulose-Ram, C. F. Dillon, Q. Gu, and J. P. Hughes, "Prevalence of peripheral arterial disease and risk factors in persons aged 60 and older: data from the National Health and Nutrition Examination Survey 1999-2004," Journal of the American Geriatrics Society, vol. 55, no. 4, pp. 583-589, 2007.

[4] A. T. Hirsch, M. H. Criqui, D. Treat-Jacobson et al., "Peripheral arterial disease detection, awareness, and treatment in primary care," The Journal of the American Medical Association, vol. 286, no. 11, pp. 1317-1324, 2001.

[5] M. H. Criqui, R. L. McClelland, M. M. McDermott et al., "The ankle-brachial index and incident cardiovascular events in the MESA (Multi-Ethnic Study of Atherosclerosis)," Journal of the American College of Cardiology, vol. 56, no. 18, pp. 1506-1512, 2010.

[6] Y. Araki, H. Kumakura, H. Kanai et al., "Prevalence and risk factors for cerebral infarction and carotid artery stenosis in peripheral arterial disease," Atherosclerosis, vol. 223, no. 2, pp. 473-477, 2012.

[7] H. E. Resnick, R. S. Lindsay, M. M. McDermott et al., "Relationship of high and low ankle brachial index to all-cause and cardiovascular disease mortality: the Strong Heart study," Circulation, vol. 109, no. 6, pp. 733-739, 2004.

[8] C. L. Heald, F. G. R. Fowkes, G. D. Murray, and J. F. Price, "Risk of mortality and cardiovascular disease associated with the ankle-brachial index: systematic review," Atherosclerosis, vol. 189, no. 1, pp. 61-69, 2006.

[9] Y. Y. Luo, J. Li, Y. Xin, L. Q. Zheng, J. M. Yu, and D. Y. Hu, "Risk factors of peripheral arterial disease and relationship between low ankle brachial index and mortality from all-cause and cardiovascular disease in Chinese patients with hypertension," Journal of Human Hypertension, vol. 21, no. 6, pp. 461-466, 2007.

[10] H.-M. Su, T.-H. Lin, P.-C. Hsu et al., "Association of chronic kidney disease and peripheral artery disease with inappropriate left ventricular mass," PLOS ONE, vol. 7, no. 10, Article ID e48422, 2012.

[11] S. Rizvi, H. Kamran, L. Salciccioli, F. Saiful, J. Lafferty, and J. M. Lazar, "Relation of the ankle brachial index to left ventricular ejection fraction," American Journal of Cardiology, vol. 105, no. 1, pp. 129-132, 2010.

[12] E. K. Kim, P. S. Song, J. H. Yang et al., "Peripheral artery disease in Korean patients undergoing percutaneous coronary intervention: prevalence and association with coronary artery disease severity," Journal of Korean Medical Science, vol. 28, no. 1, pp. 87-92, 2013.

[13] J. G. Regensteiner, W. R. Hiatt, J. R. Coll et al., "The impact of peripheral arterial disease on health-related quality of life in 
the Peripheral Arterial Disease Awareness, Risk, and Treatment: New Resources for Survival (PARTNERS) program," Vascular Medicine, vol. 13, no. 1, pp. 15-24, 2008.

[14] M. M. McDermott, P. Greenland, J. M. Guralnik et al., "Depressive symptoms and lower extremity functioning in men and women with peripheral arterial disease," Journal of General Internal Medicine, vol. 18, no. 6, pp. 461-467, 2003.

[15] M. T. Alzamora, R. Forés, J. M. Baena-Díez et al., “The Peripheral Arterial Disease study (PERART/ARTPER): prevalence and risk factors in the general population," BMC Public Health, vol. 10, article 38, 2010.

[16] L. H. Eraso, E. Fukaya, E. R. Mohler, D. Xie, D. Sha, and J. S. Berger, "Peripheral arterial disease, prevalence and cumulative risk factor profile analysis," European Journal of Preventive Cardiology, vol. 21, no. 6, pp. 704-711, 2014.

[17] M. L. Melamed, P. Muntner, E. D. Michos et al., "Serum 25-hydroxyvitamin D levels and the prevalence of peripheral arterial disease: results from NHANES 2001 to 2004," Arteriosclerosis, Thrombosis, and Vascular Biology, vol. 28, no. 6, pp. 1179-1185, 2008.

[18] N. Khandanpour, Y. K. Loke, F. J. Meyer, B. Jennings, and M. P. Armon, "Homocysteine and peripheral arterial disease: systematic review and meta-analysis," European Journal of Vascular and Endovascular Surgery, vol. 38, no. 3, pp. 316-322, 2009.

[19] L. Norgren, W. R. Hiatt, J. A. Dormandy et al., "Inter-society consensus for the management of peripheral arterial disease (TASC II)," European Journal of Vascular and Endovascular Surgery, vol. 33, no. 1, supplement, pp. S1-S75, 2007.

[20] A. Moran, M. Forouzanfar, U. Sampson, S. Chugh, V. Feigin, and G. Mensah, "The epidemiology of cardiovascular diseases in sub-saharan Africa: the global burden of diseases, injuries and risk factors 2010 study," Progress in Cardiovascular Diseases, vol. 56, no. 3, pp. 234-239, 2013.

[21] M. H. Criqui, V. Vargas, J. O. Denenberg et al., "Ethnicity and peripheral arterial disease: the San Diego Population Study," Circulation, vol. 112, no. 17, pp. 2703-2707, 2005.

[22] A. K. Paul, B. Mash, and G. Rupesinghe, "Peripheral arterial disease-high prevalence in rural black South Africans," South African Medical Journal, vol. 97, no. 4, pp. 285-288, 2007.

[23] B. O. Oyelade, A. D. Olaolorun, L. O. Odeigah, I. O. Amole, and S. A. Aderibigbe, "The relationship between obesity and peripheral arterial disease in adult Nigerian diabetics," The Nigerian Postgraduate Medical Journal, vol. 21, no. 1, pp. 57-60, 2014.

[24] A. T. Hirsch, T. P. Murphy, M. B. Lovell et al., "Gaps in public knowledge of peripheral arterial disease: the first national PAD public awareness survey," Circulation, vol. 116, no. 18, pp. 20862094, 2007.

[25] H. M. Ismail, K. Jackson, and D. Smith, "Diagnosis and treatment of peripheral arterial disease compared with other atherosclerotic vascular diseases in a university primary care clinic," Journal of Investigative Medicine, vol. 54, no. 5, pp. 255261,2006

[26] Censo, 2014, http://aiangola.com/wp-content/uploads/2016/03/ Publica\%C3\%A7\%C3\%A3o-Resultados-Definitivos-CensoGeral-2014_Vers\%C3\%A3o-22032016_DEFINITIVA-18H17.pdf.

[27] V. Aboyans, M. H. Criqui, P. Abraham et al., "Measurement and interpretation of the Ankle-Brachial Index: a scientific statement from the American Heart Association," Circulation, vol. 126, no. 24, pp. 2890-2909, 2012.
[28] X. Guo, J. Li, W. Pang et al., "Sensitivity and specificity of anklebrachial index for detecting angiographic stenosis of peripheral arteries," Circulation Journal, vol. 72, no. 4, pp. 605-610, 2008.

[29] R. M. Mwebaze and D. Kibirige, "Peripheral arterial disease among adult diabetic patients attending a large outpatient diabetic clinic at a national referral hospital in Uganda: a descriptive cross sectional study," PLoS ONE, vol. 9, no. 8, Article ID e105211, 2014.

[30] A. O. Ogbera, O. Adeleye, B. Solagberu, and A. Azenabor, "Screening for peripheral neuropathy and peripheral arterial disease in persons with diabetes mellitus in a Nigerian University Teaching Hospital," BMC Research Notes, vol. 8, no. 1, article 533, 2015

[31] E. M. Umuerri, V. A. Josephs, and A. O. Obasohan, "Determination of lower extremity peripheral artery disease: the role for automated oscillometric measurement of ankle brachial index in Nigerians," The Nigerian Postgraduate Medical Journal, vol. 20, no. 4, pp. 305-310, 2013.

[32] M. Guerchet, V. Aboyans, P. Mbelesso et al., "Epidemiology of peripheral artery disease in elder general population of two cities of central Africa: Bangui and Brazzaville," European Journal of Vascular and Endovascular Surgery, vol. 44, no. 2, pp. 164-169, 2012.

[33] D. Adeloye and C. Basquill, "Estimating the prevalence and awareness rates of hypertension in Africa: a systematic analysis," PLoS ONE, vol. 9, no. 8, Article ID e104300, 2014.

[34] V. Hall, R. Thomsen, O. Henriksen, and N. Lohse, "Diabetes in Sub Saharan Africa 1999-2011: epidemiology and public health implications. A systematic review," BMC Public Health, vol. 11, article 564, 2011.

[35] D. P. Capingana, P. Magalhães, A. B. T. Silva et al., "Prevalence of cardiovascular risk factors and socioeconomic level among public-sector workers in Angola," BMC Public Health, vol. 13, no. 1, article 732, 2013.

[36] F. G. R. Fowkes, G. D. Murray, I. Butcher et al., "Ankle brachial index combined with Framingham risk score to predict cardiovascular events and mortality: a meta-analysis," The Journal of the American Medical Association, vol. 300, no. 2, pp. 197-208, 2008.

[37] M. Guerchet, P. Mbelesso, A. M. Mouanga et al., "Association between a low ankle-brachial index and dementia in a general elderly population in Central Africa (epidemiology of dementia in Central Africa study)," Journal of the American Geriatrics Society, vol. 61, no. 7, pp. 1135-1140, 2013.

[38] P. P. Aung, H. Maxwell, R. G. Jepson, J. Price, and G. C. Leng, "Lipid-lowering for peripheral arterial disease of the lower limb," Cochrane Database of Systematic Reviews, no. 4, Article ID CD000123, 2007.

[39] C. Rosendorff, H. R. Black, C. P. Cannon et al., "Treatment of hypertension in the prevention and management of ischemic heart disease: a scientific statement from the American Heart Association council for high blood pressure research and the councils on clinical cardiology and epidemiology and prevention," Circulation, vol. 115, no. 21, pp. 2761-2788, 2007.

[40] M. A. Allison, M. Cushman, C. Solomon et al., "Ethnicity and risk factors for change in the ankle-brachial index: the MultiEthnic Study of Atherosclerosis," Journal of Vascular Surgery, vol. 50, no. 5, pp. 1049-1056, 2009.

[41] M. N. Loja, A. Brunson, C.-S. Li et al., "Racial disparities in outcomes of endovascular procedures for peripheral arterial disease: an evaluation of California hospitals, 2005-2009," Annals of Vascular Surgery, vol. 29, no. 5, pp. 950-959, 2015. 
[42] A. K. Jain, C. A. Kalbaugh, M. A. Farber, W. A. Marston, and R. Vallabhaneni, "Race and gender affect outcomes of lower extremity bypass," Journal of Vascular Surgery, vol. 60, no. 5, pp. 12751280, 2014.

[43] T. A. Meadows, D. L. Bhatt, C. P. Cannon et al., "Ethnic differences in cardiovascular risks and mortality in atherothrombotic disease: insights from the Reduction of Atherothrombosis for Continued Health (REACH) registry," Mayo Clinic Proceedings, vol. 86, no. 10, pp. 960-967, 2011. 


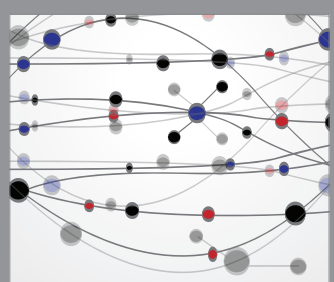

The Scientific World Journal
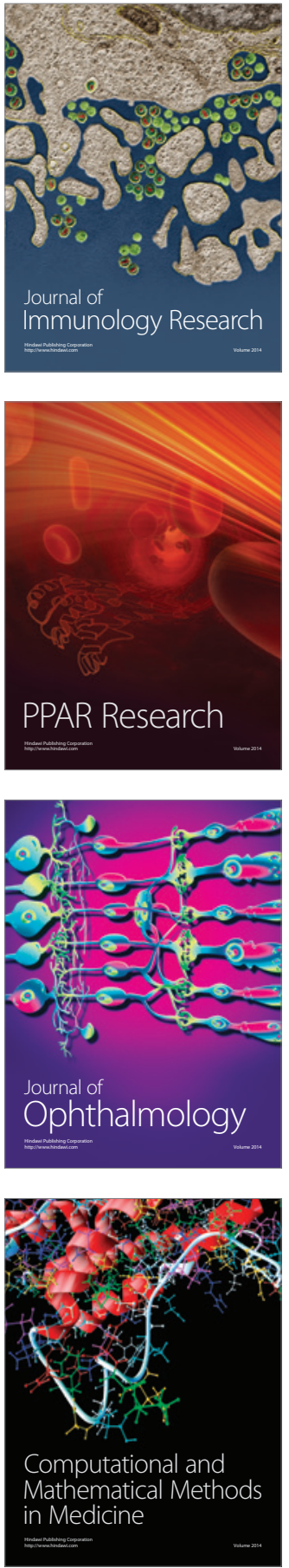

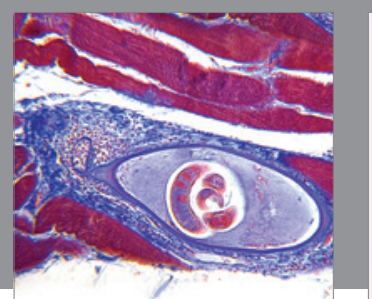

Gastroenterology Research and Practice

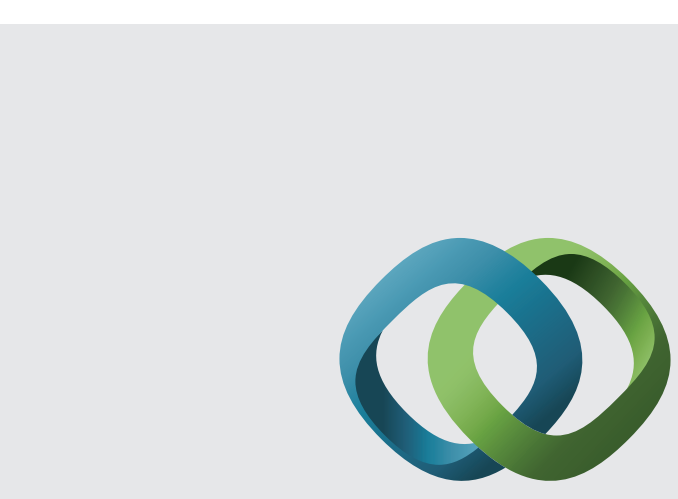

\section{Hindawi}

Submit your manuscripts at

http://www.hindawi.com
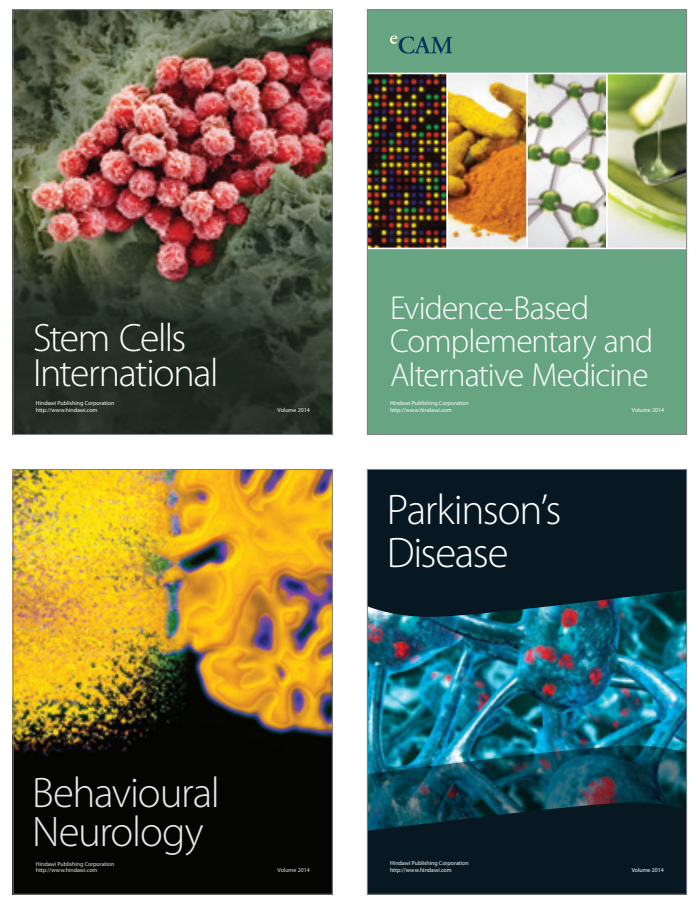
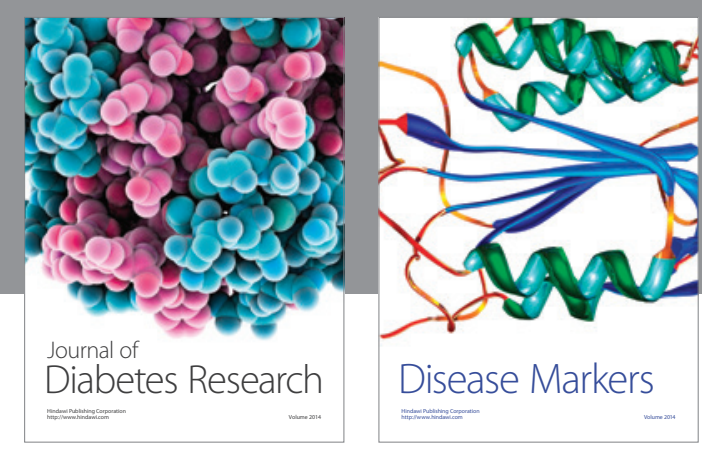

Disease Markers
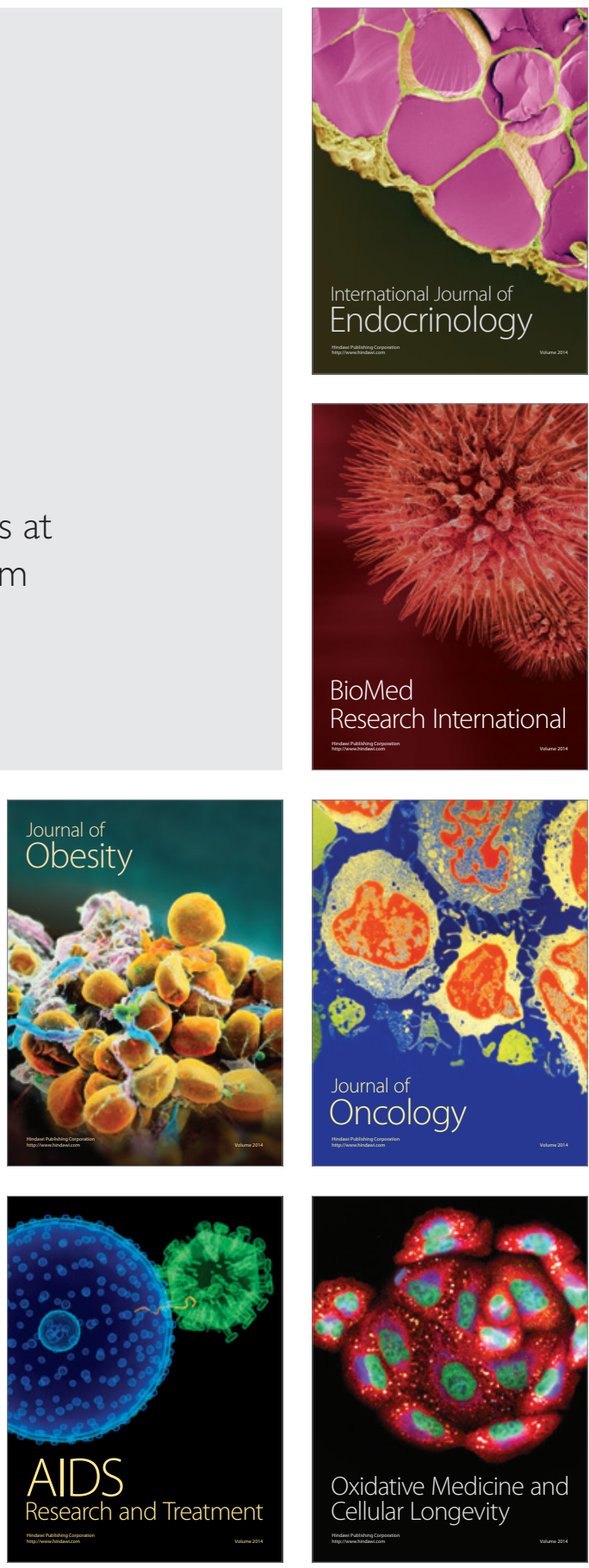